\title{
Pengaruh Program Layanan Jemput Maslahah Terhadap Intensitas Penggunaan Tabungan Mudharabah
}

\section{Effect of program layanan jemput maslahah on the intensity of using mudharabah savings}

\section{Nisa Fajriati Nurfaridah}

Program Studi D4 Keuangan Syariah, Politeknik Negeri Bandung

E-mail: nisa.fajriati.ksy15@polban.ac.id

\begin{abstract}
Program Layanan Jemput Maslahah is a service provided by BJB Syariah Bank to meet customer needs by visiting customers directly to accommodate customers' transaction needs quickly and easily. This research is an evaluation of a program issued by BJB Syariah Bank. This study aims to analyze the effect of the program layanan jemput maslabah, satisfaction and trust as a mediating variable on the intensity of the use of mudharabah savings. In this study the population consisted of customers in two Bank BJB Syariah Sub-Branch Offices spread across the Regency of Bandung. The samples used in this study were 125 customers of the Syariah BJB Bank in Bandung Regency. The data used is primary data in the form of a closed questionnaire. The data analysis method used is descriptive data analysis and quantitative data analysis. The tool used to analyze data in research is SmartPLS 2.0. The results of this study indicate that Layanan Jemput Maslahah has a positive influence on the Intensity of the Use of Mudharabah Savings and Satisfaction and Trust can positively mediate between Layanan Jemput Maslabah and the Intensity of the Use of Mudharabah Savings.
\end{abstract}

Keywords: Layanan Jemput Maslabah Program, Satisfaction, Trust, Intensity Use of Mudharabah Savings

\section{Pendahuluan}

Indonesia merupakan negara dengan memiliki jumlah penduduk muslim terbesar di dunia (Rama, 2015). Populasi penduduk muslim di Indonesia mencapai 87,21\% pada tahun 2016 (Kemenag, 2016). Dengan pencapaian populasi yang mendekati $90 \%$ tidak menjamin akan meningkatnya suatu tabungan khususnya di bank syariah Indonesia. Rendahnya minat menabung masyarakat dapat tercermin dari market share perbankan di Indonesia (Suhartanto dkk., 2020). Pertumbuhan market share perbankan syariah dari tahun ke tahun mengalami peningkatan hampir $6 \%$ namun hal ini masih berbeda jauh dengan market share perbankan konvensional yang sudah mencapai 94,06\% (OJK, 2019). Selain dilihat dari populasi muslim di Indonesia dapat dilihat juga dari disrupsi digital di zaman sekarang. Perubahan disrupsi digital ini sudah mulai menjadi tantangan bagi industri perbankan dengan adanya financial technology (Fintech). Adanya disrupsi digital membuat bank harus mengubah cara berpikir dari yang selama ini hanya menunggu nasabah yang datang dan menyimpan uang, kini harus lebih dinamis dan aktif. Terlebih pada saat ini nasabah ingin sesuatu yang lebih mudah dalam bertransaksi perbankan.

Salah satu cara agar market share naik yaitu dengan cara pendekatan kepada nasabah, dengan langkah pertama yaitu membuka rekening dalam produk tabungan khususnya tabungan mudharabah. Pendekatan ini dapat disebut dengan personal selling. Personal selling merupakan penyajian lisan dalam suatu percakapan yang dilakukan oleh satu atau lebih calon pembeli agar calon pembeli dapat membelinya (Zuliatin, 2016). Untuk melakukan suatu interaksi dengan nasabah pihak perbankan 
konvensional maupun perbankan syariah hanya melakukan perbaikan di lingkungan intern saja, seperti hanya menambah produk yang dikeluarkan oleh bank syariah ataupun hanya menambah kantor kas cabang. Perbaikan di lingkungan intern tidak akan menjamin akan menambahnya nasabah. Masyarakat selaku konsumen mengharapkan adanya pelayanan yang baik untuk memenuhi kebutuhan dan keinginannya. Kepuasan merupakan respon atau tanggapan dari konsumen mengenai pemenuhan kebutuhan. Kepuasan merupakan penilaian mengenai ciri atau keistimewaan produk atau jasa, atau produk itu sendiri, yang menyediakan tingkat kesenangan konsumen berkaitan dengan pemenuhan kebutuhan konsumsi konsumen. Selain dilihat dari kepuasan, kepercayaan juga merupakan faktor utama bagi calon nasabah untuk memilih produk atau layanan jasa yang ada di bank syariah. Kepercayaan melibatkan seseorang untuk berperilaku tertentu karena nasabah meyakini bahwa mitranya dalam melakukan suatu transaksi akan memberikan harapan yang baik. Hal ini akan menunjukan apabila satu pihak sudah percaya kepada pihak lainnya maka akan membentuk suatu perilaku yang baik. Apabila nasabah merasa puas dan percaya terhadap jasa yang diberikan oleh bjb Syariah maka hal ini akan mempengaruhi tingkat tabungan yang ada di Bank BJB Syariah. Semakin banyak nasabah yang percaya dan merasa puas dengan jasa yang diberikan pihak bank maka akan semakin meningkat jumlah tabungan yang ada di BJB Syariah. Dengan demikian pengaruh program layanan jemput maslahah terhadap intensitas penggunaan tabungan mudharabah dapat berpengaruh positif dengan kepercayaan dan kepuasan dijadikan sebagai variabel mediasi. Selama ini sistem personal selling hanya berlaku di perusahaan transportasi online (Ruslianor Maika, 2017) dan lembaga amil zakat (Erliana, 2018) namun belum dikembangkan di perbankan syariah. Oleh sebab itu, penulis memandang perlunya pengembangan teori personal selling dalam konteks peningkatan jumlah Tabungan Bank Syariah. Layanan Jemput Maslahah merupakan representasi dari teori tersebut yang akan diuji dalam penelitian ini.

Berdasarkan latar belakang diatas, maka rumusan masalah penilitian ini adalah sebagi berikut:

1. Apakah program layanan jemput maslahah mempengaruhi jumlah Tabungan Mudharabah secara positif?

2. Apakah kepuasan dapat memediasi secara positif hubungan antara layanan jemput maslahah dengan Tabungan Mudharabah?

3. Apakah kepercayaan dapat memediasi secara positif hubungan antara layanan jemput maslahah dengan Tabungan Mudharabah?

Tujuan penelitian adalah untuk mengetahui program layanan jemput maslahah dapat mempengaruhi jumlah Tabungan Mudharabah secara positif, mengetahui kepuasan dan kepercayaan dapat memediasi secara positif hubungan antara layanan jemput maslahah dengan Tabungan Mudharabah.

\section{Kajian Pustaka}

\subsection{Hubungan Langsung Layanan Jemput Maslahah dan Intensitas Tabungan}

Penjualan pribadi (personal selling) adalah suatu interaksi dengan adanya tatap muka dengan satu atau banyak konsumen dengan tujuan untuk membuat suatu presentasi, menjawab pertanyaan dan pengadaan suatu objek (Panjaitan, 2016). Dalam perbankan kegiatan personal selling dilakukan oleh pegawai bank dari pejabat bank hingga tenaga salesman dan salesgirl untuk melakukan door to door. Dilihat dari kondisi persaingan dalam usaha yang semakin ketat, layanan jemput bola (personal selling) ini sangat dibutuhkan. Hal ini dimaksudkan untuk memberikan kemudahan bagi calon nasabha, agar nasabah merasa mudah dengan pelayanan terhadap produk/jasa yang ditawarkan. Maka dari itu pegawai bank yang melakukan personal selling harus memberikan solusi secara kreatif untuk menghadapi masalah nasabah, sehingga dari personal selling akan timbul kedekatan antara pihak bank dan nasabah (Murithi, 2015). Dalam menggunakan sistem jemput bola ini bukan hanya 
saja untuk memasarkan suatu produk, tetapi menjual lembaga keuangan itu sendiri terhadap masyarakat. Sehingga, nasabah tidak hanya mempercayai dana yang dititipkan kepada pegawai bank namun percaya terhadap semua operasional yang dilakukan oleh pihak bank.

Dilihat dari teori personal selling, layanan jemput maslahah ini memiliki kesamaan cara, yaitu keduanya sama-sama menjemput calon nasabah baik ke nasabah sendiri, kepada komunitas atau ke instansi agar menjadi nasabah di Bank BJB Syariah. Calon nasabah tersebut akan dipermudah apabila ingin membuka rekening. Dalam program Layanan Jemput Maslahah ini teknik yang dilakukan dengan diam di satu titik lalu bagi siapa saja yang akan menabung datang ke tempat tersebut. Layanan jemput maslahah ini tidak langsung menawarkan produk yang akan dipasarkan tetapi pihak bank akan bersilaturahmi terlebih dahulu agar calon nasabah merasa nyaman. Dalam Layanan Jemput Maslahah ini hanya melakukan transaksi penghimpunan dana. Antara layanan jemput maslahah dengan intensitas menabung ini dapat saling mempengaruhi, karena apabila calon nasabah sudah percaya terhadap apa yang disampaikan oleh pihak bank maka calon nasabah ini akan membuka rekening tabungan di Bank BJB Syariah. Dalam penelitian yang dilakukan oleh Adewale dkk, (2019) bahwa personal selling dapat meningkatkan penjualan PZ and Dangote Nigeria PLC. Sehingga dapat diambil kesimpulan bahwa program layanan jemput maslahah yang merupakan sistem personal selling dapat mempengaruhi tabungan mudharabah secara positif. . Oleh sebab itu munculah $\mathrm{H}_{1}$ yang rumusannya sebagai berikut :

$H_{1}$ : Program Layanan Jemput Maslahah mempengarubi jumlah Tabungan Mudharabah secara positif.

\subsection{Peran Kepuasan Dalam Memediasi Layanan Jemput Maslahah dan Intensitas Tabungan}

Pada saat ini salah satu cara bagaimana perusahaan bisa unggul dibanding perusahaan lain yaitu dengan cara memberikan layanan kepada calon nasabah. Kepuasan merupakan suatu faktor utama dalam menilai kualitas yang diberikan, yang dimana konsumen menilai kinerja dan pelayanan yang sudah diterima serta produk yang didapatkan. Apabila kinerja suatu perusahaan khususnya bank syariah dibawah harapan maka nasabah akan kecewa. Begitupun sebaliknya apabila perusahaan memberikan kinerja melebihi haparan nasabah maka nasabah akan merasa puas. Kepuasan merupakan upaya pemenuhan sesuatu yang sudah tercapai. Kepuasan bagi nasabah merupakan respon emosional yang dapat ditemukan dengan proses intropeksi, yaitu tindakan identifikasi konseptual yang diarahkan pada isi dan proses mental seorang nasabah (Appasaheb, 2018).

Pada saat nasabah merasakan kepuasan tehadap proses transaksi dan puas terhadap barang dan jasa, besar kemungkinan nasabah tersebut akan kembali melaukan pembelian dan akan merekomendasikan kepada teman atau keluarga tentang bank tersebut serta kecil kemungkinan nasabah tersebut akan berpaling kepada perusahaan lainnya atau perbankan lain (Almana dkk, 2018).

Apabila dari produk/jasa mampu memberikan pengalaman yang positif yang tidak terlupakan (memorable experience) yang menyentuh sisi afeksi nasabah, nasabah akan selalu mengingat produk/jasa tersebut ketika akan menggunakannya. Dalam penelitian yang dilakukan oleh Erliana (2018), bahwa terdapat pengaruh yang signifikan antara layanan jemput zakat terhadap kepuasan muzakki di Lembaga Amil Zakat Yatim Mandiri Cabang Jombang. Berdasarkan penjelasan di atas variabel kepuasan memiliki kemampuan mediasi variabel layanan jemput maslahah dengan tabungan mudharabah secara meyakinkan. Maka lahirlah $\mathrm{H}_{2}$ yang penulis nyatakan sebagai berikut : $\mathrm{H}_{2}$ : Kepuasan dapat memediasi secara positif hubungan antara layanan jemput maslabah dengan Tabungan Mudharabah. 


\subsection{Peran Kepercayaan dalam Memediasi Layanan Jemput Maslahah dan Intensitas Tabungan}

Kepercayaan merupakan sikap yakin terhadap beberapa kualitas atau atribut dari suatu objek atau seseorang (Damsar dan Indrayani, 2016). Kepercayaan merupakan peran mendasar dalam hubungan timbal balik dan membentuk perilaku interaksi para pihak yang terlibat (Luk dkk, 2018). Kepercayaan merupakan ekspektasi seseorang bahwa ucapan tersebut dapat diandalkan dengan baik (Sahanggamu dkk, 2015). Kepercayaan merupakan hal yang penting bagi setiap orang untuk membangun suatu kepuasan, walaupun pihak yang dipercaya sangatlah sulit untuk membangun sutau kepercayaan. Membangun suatu kepercayaan sangatlah sulit untuk didefinisikan secara eksplisit karena individu memiliki berbagai masalah dalam tingkat kepercayaan mereka kepada lembaga keuangan (Fungá ${ }^{\sim}$ dkk, 2017). Berdasarkan pada penjelasan di atas, variabel kepercayaan memiliki kapasitas yang sangat kuat dalam memediasi layanan jemput maslahah dengan tabungan mudharabah. Hipotesis yang dapat dirumuskan dari pernyataan tersebut adalah sebagai berikut:

Berikut merupakan gambaran mengenai struktur model yang akan diteliti :

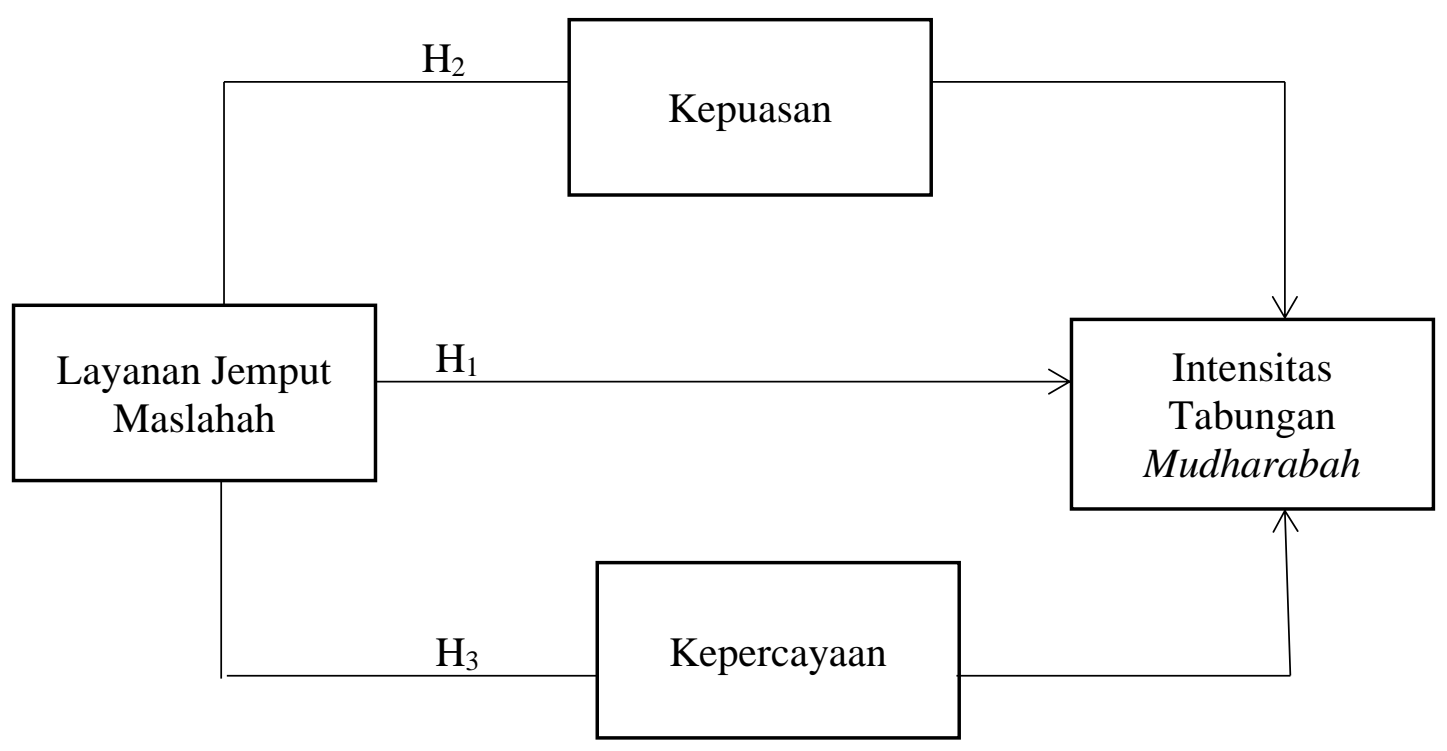

Gambar 1. Struktur Model

\section{Metode Penelitian}

Analisis data yang digunakan dalam penelitian ini adalah analisis data deskriptif dan analisis data kuantitatif. Analisis deskriptif mengacu kepada teknik transformasi data mentah kedalam bentuk yang mudah dimengerti dan diterjemahkan (Wibisono, 2003). Penelitian ini memanfaatkan indikator yang menggambarkan karakteristik nasabah seperti jenis kelamin, umur, pendidikan terakhir, serta pekerjaan atau profesi dari nasabah tersebut yang digunakan dalam pengambilan sampel yaitu purposive sampling, purposive sampling merupakan teknik pengambilan sampel dengan memiliki pertimbangan tertentu (Sugiyono, 2018). Adanya penentuan sampel berdasarkan beberapa kriteria:

1. Berdomisili di Kabupaten Bandung

2. Nasabah yang mempunyai Tabungan Mudharabah

3. Nasabah yang sudah menggunakan Program Layanan Jemput Maslahah

Populasi dalam penelitian ini yaitu nasabah yang berada di dua kantor cabang pembantu Bank BJB Syariah di wilayah Kabupaten Bandung. Sedangkan sampel dalam penelitian ini adalah 
125 nasabah yang sudah menggunakan program layanan jemput maslahah. Instrumen yang digunakan dalam penelitian ini adalah berupa kuesioner tertutup yang berisi pernyataan yang tidak memberikan kebebasan sehingga responden tidak menjawab yang tidak sesuai dengan harapan peneliti (Wibisono, 2003). Sistem yang digunakan berupa pemberian skor berdasarkan skala likert, dimana responden akan menyatakan pernyataan dari setuju hingga tidak setuju (Sugiyono, 2018). Teknik analisis data ini menggunakan alat SmartPLS 2.0 .

\section{Hasil dan Pembahasan}

Pengukuran model SmartPLS2.0 ini terbagi menjadi tiga tahap yaitu berdasarkan pada pengukuran evaluasi outer model, inner model dan uji hipotesis.

\subsection{Hubungan Langsung Layanan Jemput Maslahah dan Intensitas Tabungan}

Evaluasi outer model dapat diukur melalui convergent validity, dimana nilai tersebut dapat signifikan apabila >0,5 (Mutaqqin dan Dharmayanti 2015). Serta dapa diukur dari uji reabilitas yaitu discriminant validity, nilai tersebut akan dikatakan baik apabila $>0,5$ (Usada dkk, 2016). Hasil perhitungan yang sudah dilakukan menunjukan semua indikator memenuhi syarat dalam pengujian model Partial Least Squares (PLS). Berdasarkan dari hasil perhitungan dapat diperoleh convergent validity dan discriminate vallidity sebagai berikut:

Tabel 1. AVE dan Communality

\begin{tabular}{|c|c|c|}
\hline & AVE & Communality \\
\hline ITM & 0.659512 & 0.659512 \\
\hline LJM & 0.748845 & 0.748845 \\
\hline SAT & 0.617608 & 0.617608 \\
\hline TR & 0.685592 & 0.685592 \\
\hline
\end{tabular}

Sumber : Pengolahan data dengan SmartPLS, 2019

Sedangkan nilai dari discriminate validity adalah sebagai berikut:

Tabel 2. Cross Loading

\begin{tabular}{|c|c|c|c|c|}
\hline & ITM & LJM & SAT & TR \\
\hline ITM1 & $\mathbf{0 . 8 1 6 0 6 8}$ & 0.429164 & 0.518678 & 0.500776 \\
\hline ITM2 & $\mathbf{0 . 8 5 0 8 5 6}$ & 0.381013 & 0.447618 & 0.503670 \\
\hline ITM3 & $\mathbf{0 . 8 4 5 4 4 7}$ & 0.448504 & 0.576008 & 0.616369 \\
\hline ITM4 & $\mathbf{0 . 8 1 5 4 0 3}$ & 0.481407 & 0.547616 & 0.545365 \\
\hline ITM5 & $\mathbf{0 . 7 2 6 6 1 7}$ & 0.318567 & 0.471472 & 0.460932 \\
\hline LJM1 & 0.488263 & $\mathbf{0 . 8 7 2 5 7 3}$ & 0.638912 & 0.587933 \\
\hline LJM2 & 0.465364 & $\mathbf{0 . 8 2 4 2 3 7}$ & 0.588754 & 0.583906 \\
\hline LJM3 & 0.416912 & $\mathbf{0 . 8 4 6 0 9 6}$ & 0.615534 & 0.578087 \\
\hline LJM4 & 0.485506 & $\mathbf{0 . 8 7 5 7 7 6}$ & 0.603260 & 0.589065 \\
\hline LJM5 & 0.456169 & $\mathbf{0 . 8 8 9 1 2 4}$ & 0.630832 & 0.590414 \\
\hline LJM6 & 0.382292 & $\mathbf{0 . 8 9 7 1 8 0}$ & 0.570311 & 0.545703 \\
\hline LJM7 & 0.389849 & $\mathbf{0 . 8 5 0 1 9 1}$ & 0.574975 & 0.491929 \\
\hline SAT1 & 0.512259 & 0.560099 & $\mathbf{0 . 8 0 2 4 3 7}$ & 0.610353 \\
\hline SAT2 & 0.463320 & 0.502222 & $\mathbf{0 . 7 8 4 5 0 6}$ & 0.546892 \\
\hline SAT3 & 0.472089 & 0.541189 & $\mathbf{0 . 7 4 4 2 9 6}$ & 0.562975 \\
\hline SAT4 & 0.522527 & 0.605461 & $\mathbf{0 . 8 1 1 0 6 7}$ & 0.632542 \\
\hline SAT5 & 0.521104 & 0.525996 & $\mathbf{0 . 7 8 5 4 1 6}$ & 0.603823 \\
\hline TR1 & 0.591165 & 0.546624 & 0.619234 & $\mathbf{0 . 8 7 6 3 5 8}$ \\
\hline
\end{tabular}




\begin{tabular}{|r|r|r|r|r|}
\hline TR2 & 0.503404 & 0.534824 & 0.617233 & $\mathbf{0 . 7 9 6 8 0 3}$ \\
\hline TR3 & 0.553163 & 0.523051 & 0.630169 & $\mathbf{0 . 8 1 6 6 4 1}$ \\
\hline TR4 & 0.532032 & 0.505364 & 0.577657 & $\mathbf{0 . 8 2 1 3 4 6}$ \\
\hline TR5 & 0.517446 & 0.606837 & 0.675108 & $\mathbf{0 . 8 2 6 7 7 1}$ \\
\hline
\end{tabular}

Sumber : Data Primer yang diolah (2019)

Selain dari pengukuran uji validitas dan realibitas untuk evaluasi outer model dapat dilihat dari composite reliability dan cronbach's alpa. Berikut merupakan hasil dari composite reliability dan cronbach's alpa menggunakan SmartPLS 2.0 :

Table 3. Composite Reliability dan Cronbach's Alpha

\begin{tabular}{|c|c|c|}
\hline Construct & $\begin{array}{c}\text { Composite } \\
\text { Reliability }\end{array}$ & Cronbach's Alpha \\
\hline ITM & 0.906153 & 0.870112 \\
\hline LJM & 0.954244 & 0.943970 \\
\hline SAT & 0.889730 & 0.845022 \\
\hline TR & 0.915909 & 0.885028 \\
\hline
\end{tabular}

Sumber : Pengolahan data dengan SmartPLS 2.0 (2019)

Menurut Rahmi dkk, (2017) konstruk dinyatakan reliabel jika memiliki nilai composite reliability $>0,70$ dan cronbach's alpha $>0,60$.

\subsection{Evaluasi Inner Model}

Evaluasi inner model dalam SmartPLS menggunakan R-square untuk variabel dependen dan nilai koefisien path untuk variabel independen yang kemudian akan dinilai kesignifikanannya berdasarkan nilai t-statistic setiap path. Berikut model struktual penelitian:

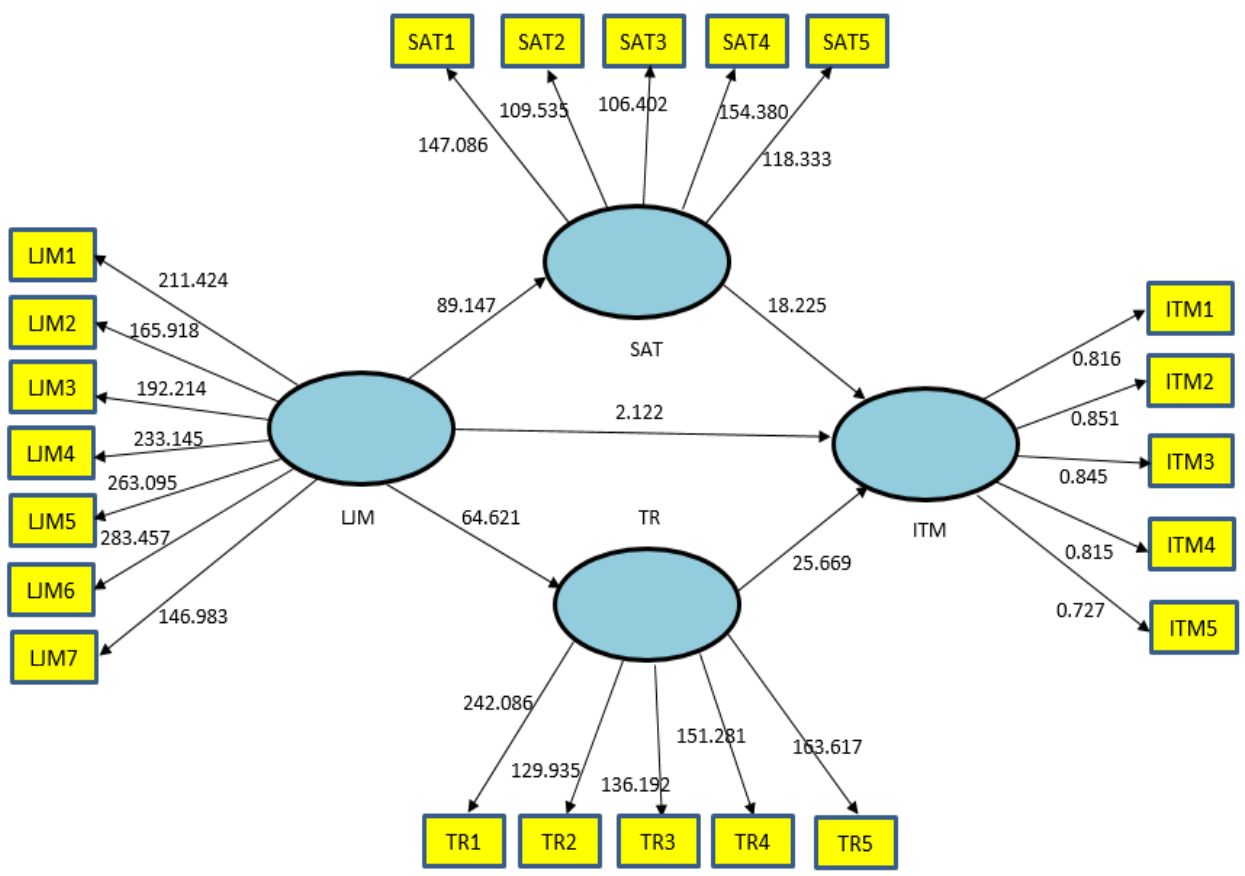

Gambar 2. Tampilan Hasil SmartPLS Boothstrapping 
Untuk menilai signifikan model prediksi, dapat dilihat dari nilai $t$-statistic antara variabel independen ke variabel dependen dalam tabel Path Coefficient pada output berikut ini :

Tabel 4. Nilai R-square

\begin{tabular}{|c|c|}
\hline & $\boldsymbol{R}$-square \\
\hline ITM & 0.473376 \\
\hline LJM & \\
\hline SAT & 0.488058 \\
\hline TR & 0.431690 \\
\hline
\end{tabular}

Sumber: Output SmartPLS (2019)

Semakin tinggi nilai $R$-square, maka akan semakin besar kemampuan variabel independen dan dapat menjelaskan variabel dependen sehingga akan memberikan persamaan struktual yang sangat baik (Fitria, 2015).

Tabel 5. Path Coefficients (Mean, STDEV, t-Value)

\begin{tabular}{|l|c|c|c|c|c|}
\hline & $\begin{array}{c}\text { Original } \\
\text { Sample (O) }\end{array}$ & $\begin{array}{c}\text { Sample } \\
\text { Mean (M) }\end{array}$ & $\begin{array}{c}\text { Standard } \\
\text { Deviation } \\
\text { (STDEV) }\end{array}$ & $\begin{array}{c}\text { Standard } \\
\text { Error } \\
\text { (STERR) }\end{array}$ & $\begin{array}{c}\text { T- } \\
\text { Statistics }\end{array}$ \\
\hline LJM -> ITM & 0.033178 & 0.032943 & 0.015636 & 0.015636 & 2.121917 \\
\hline LJM -> SAT & 0.698611 & 0.698335 & 0.007837 & 0.007837 & 89.147152 \\
\hline LJM -> TR & 0.657031 & 0.656136 & 0.010167 & 0.010167 & 64.620827 \\
\hline SAT -> ITM & 0.316938 & 0.319829 & 0.017390 & 0.017390 & 18.225482 \\
\hline TR -> ITM & 0.391240 & 0.389264 & 0.015242 & 0.015242 & 25.668975 \\
\hline
\end{tabular}

Sumber : Data Primer yang diolah (2019)

\subsubsection{Pengujian Hipotesis $\mathrm{H}_{1}$}

Hipotesis pertama menyatakan bahwa Program Layanan Jemput Maslahah mempengaruhi jumlah Tabungan Mudharabah secara positif. Berdasarkan hasil dari data yang sudah diolah Layanan Jemput Maslahah memiliki nilai original sample estimate sebesar 0.033178 serta memiliki nilai t-statistik sebesar 2.121917 yang berada jauh diatas nilai $>1,96$. Sehingga dari hasil tersebut menunjukan bahwa Program Layanan Jemput Maslahah mampu meningkatkan Tabungan Mudharabah secara positif.

\subsubsection{Pengujian Hipotesis $\mathbf{H}_{2}$}

Pengujian hipotesis kedua dilakukan untuk mengetahui apakah Kepuasan dapat memediasi secara positif hubungan antara Layanan Jemput Maslahah dengan Tabungan Mudharabah. Dilihat dari tabel 4.6 hasil tersebut menunjukan bahwa nilai original sample estimate sebesar 0.316938 dan memiliki nilai t-statistik sebesar 18.225482 yang berarti bahwa hasil tersebut sudah memenuhi syarat karena $>1,96$.

\subsubsection{Pengujian Hipotesis $\mathbf{H}_{3}$}

Pengujian hipotesis ketiga ditujukan untuk melihat apakah Kepercayaan dapat memediasi secara positif hubungan antara Layanan Jemput Maslahah dengan Tabungan Mudharabah. Berdasarkan hasil dari data yang sudah diolah kepuasan memiliki nilai original sample estimate sebesar 0.391240 dan memilki nilai t-statistik sebesar 25.668975 dapat disimpulkan bahwa kepuasan berpengaruh positif terhadap Layanan Jemput Maslahah.

Untuk melakukan pengujian mediasi dapat dilakukan dengan menggunakan Uji Sobel (Sobel Test) (Honan dkk, 2015). Uji sobel dilakukan dengan melakukan pengujian untuk mengetahui seberapa signifikan antara variabel dependen ke variabel independen mealui variabel mediasi 
(Kurniawan, 2017). Hasil dari mediasi hipotesis kedua yang menyatakan kepuasan dapat memediasi hubungan antara layanan jemput maslahah dan intensitas tabungan memiliki nilai sebesar 18,27. Dan untuk hasil mediasi hipotesis ketiga yang menyatakan kepercayaan dapat memediasi hubungan anatara layanan jemput masalahan dan intensitas tabungan memiliki nilai sebesar 24,22. Menurut Yunis dkk (2017), untuk melihat hasil mediasi yang menggunakan Sobel Test memiliki nilai z-Mutlak $>$ 1,96 maka dari itu hasil kedua mediasi tersebut dapat diterima. Hasil dari Sobel Test ini didukung oleh penelitian yang dilakukan oleh Kwon dan Lee (2015), bahwa efek mediasi komorbiditas klinis pada prediktabilitas agresi remaja dengan kecanduan internet memiliki nilai $z>1,96$.

\subsection{Pembahasan}

\subsubsection{Implikasi Teoritis}

Sesuai dengan studi empiris kepuasan nasabah akan memberikan manfaat dalam jangka panjang. Dengan adanya Layanan Jemput Maslahah bagi Bank BJB Syariah akan berpengaruh positif terhadap intensitas penggunaan tabungan mudharabah, kemudian nasabah akan merasa puas dan percaya untuk loyal kepada Bank BJB Syariah. Hal ini didukung dengan penelitian yang dilakukan oleh Adewale dkk, (2019) bahwa personal selling dapat meningkatkan volume penjualan PZ and Dangote Nigeria PLC. Dapat dibuktikan kembali bahwa hasil inner model dalam penelitian ini menunjukan pengaruh positif terhadap hipotesis pertama yang menyatakan bahwa program layanan jemput maslahah mempengaruhi jumlah tabungan mudharabah. Personal selling ini masih sangat jarang diterapkan di perbankan baik konvensional khususnya perbankan syariah.

Adanya kepuasan pelanggan dalam syariah tidak hanya dilihat dari kesesuaian antara kinerja produk dengan harapan nasabah secara material, melainkan dilihat dari kinerja produk dengan harapan nasabah secara spritual. Hipotesis ke dua dari penelitian ini menyatakan kepuasan dapat memediasi secara positif hubungan antara layanan jemput maslahah dengan tabungan mudharabah, hal ini didukung dengan penelitian yang dilakukan oleh Erliana (2018), bahwa layanan jemput zakat berpengaruh signifikan terhadap kepuasan muzakki. Layanan jemput zakat tersebut sama seperti layanan jemput maslahah yang memiliki arti sebagai personal selling. Selain itu dari hasil $\mathrm{H}_{2}$ ini didukung oleh penelitian yang dilakukan oleh Zuliatin (2016), bahwa personal selling memiliki pengaruh positif dan signifikan terhadap kepuasan nasabah BMT UGT Sidogiri KCP Kanigoro Blitar. Penelitian yang dilakukan oleh Wicaksonno dkk (2015) menunjukan kembali bahwa personal selling berpengaruh terhadap kepuasan konsumen di toko bagiak pelangi sari Banyuwangi secara empirik dan terbukti signifikan. Kepuasan nasabah yang baik akan meningkatkan personal selling dan kualitas produk yang baik dimata nasabah. Apabila dari program layanan jemput maslahah Bank BJB Syariah memberikan pengalaman yang sangat baik maka akan menyentuh sisi afeksi nasabah, nasabah akan mengingat produk/jasanya ketika sudah menggunakan dan dapat memberikan hal yang positif kepada orang lain. Dalam menggunakan produk/jasa nasabah memiliki pengetahuan dan waktu yang terbatas mengenai tabungan mudharabah atau produk lainnya yang ada di Bank BJB Syariah, sehingga pesonal selling ini sangatlah penting dan harus ditingkatkan kembali agar dapat menginformasikan suatu hal yang berhubungan dengan produk yang ada di BJB Syariah.

Kemudian untuk hipotesis ketiga yang menunjukan kepercayaan dapat memediasi secara positif hubungan antara layanan jemput maslahah dengan tabungan mudharabab dapat berpengaruh yang signifikan dan memiliki nilai mediasi yang sangat bagus. Hal ini sesuai dengan penelitian yang dilakukan oleh Erliana (2018) bahwa persepsi muzakki pada indikator jujur dan dapat dipercaya memiliki hasil yang positif, bahwa karyawan dari Yatim Mandiri mampu memberikan kepercayaan kepada muzakki bahwa zakat akan disalurkan kepada mereka yang berhak menerimanya. Sama seperti muzakki di Yatim Mandiri, nasabah di Bank BJB Syariah percaya terhadap layanan-layanan yang diberikan oleh Bank BJB Syariah. Menurut Varghese dkk dalam Nuralam (2018), meyimpulkan bahwa fokus strategis organisasi jangka panjang melibatkan tenaga penjualan pribadi 
yang dapat bersikap profesional sebagai penasihat konsultatif dan memberikan informasi yang bermanfaat bagi nasabah. Nilai-nilai islam dalam praktik memperkuat kualitas seperti kejujuran, kepercayaan, kesetiaan dan fleksibilitas.

Penelitian ini memperbaharui pendapat Erliana (2018) mengenai layanan jemput zakat yang ternyata dapat digunakan pula dalam meningkatkan tabungan di perbankan syariah melalui layanan jemput maslahah. Tidak hanya itu teori personal selling (Adewale, 2019) ternyata dapat digunakan pula dalam mendukung model layanan jemput maslahah.

\subsubsection{Implikasi Manjerial}

Dari penelitian ini menunjukan bahwa tidak hanya layanan jemput zakat yang dapat memberikan pengaruh kepercayaan dan kepuasan terhadap muzakki tetapi cara yang dilakukan oleh lembaga amil zakat dapat dilakukan oleh Bank BJB syariah atau lembaga keuangan lainnya. Dari program yang dilakukan oleh Bank BJB Syariah tentu akan meningkatkan penggunaan tabungan mudharabah atau dapat meningkatkan program-progam lainnya yang ada di Bank BJB Syariah. Karena dari personal selling ini tidak hanya memberikan pelayanan terhadap tabungan mudharabah tetapi dapat memberikan informasi mengenai kebutuhan nasabah. Penelitian ini dapat dijadikan acuan bagi karyawan Bank BJB Syariah untuk meningkatkan layanan jemput maslahah. Memperbaharui strategi layanan jemput maslahah secara kreatif dan serius dalam meningkatkan tabungan mudharabah ke khalayak luas, karena melakukan program layanan jemput maslahah yang kreatif dan serius tidak hanya mendapatkan penjualan yang tinggi tetapi dapat membentuk etos kerja yang tinggi, keterampilan berkomunikasi yang lebih baik dan dapat meningkatkan keterampilan dalam melakukan pekerjaan (Wardana, 2013).

Tidak hanya dalam segi strategi yang dapat meningkatkan tabungan mudharabah, menambah sumber daya manusia merupakan upaya yang dapat dilakukan oleh BJB Syariah agar dapat menghasilkan pekerjaan yang berkualitas dan tidak akan menghambat kepada pekerjaan yang lain sehingga masing-masing pegawai memiliki tanggunga jawab dengan pekerjaan masing-masing. Meningkatkan intensitas dalam program layanan jemput maslahah. Dalam program layanan jemput maslahah dapat dijadikan sebagai kegiatan rutin seperti seminggu tiga kali sehingga hasil yang didapatkan akan lebih maksimal. Hal yang sangat penting bagi Bank BJB Syariah yaitu tetap meningkatkan kualitas serta kuantitas pelayanan terhadap seluruh nasabah di Bank BJB Syariah, sehingga diharapkan mampu memperoleh loyalitas stakholeder maupun nasabah di Bank BJB Syariah. Berdasarkan temuan riset ini bank syariah harus aktif dalam mendekati nasabah. Dalam konteks peningkatan jumlah Tabungan Syariah, program Layanan Jemput Maslahah sangat relevan dalam menjawab tuntutan tersebut. Pada upaya peningkatan produk perbankan syariah yang lain, peneliti menyarankan perbankan syariah agar menggunakan pendekatan Layanan Jemput Maslahah. Maka dari itu dengan adanya layanan jemput maslahah ini sangatlah penting untuk diterapkan oleh perbankan syariah dalam meningkatkan tabungan mudharabah khususnya market share di perbankan syariah. Sehingga perbankan syariah harus melihat cara pandang yang lebih baru yaitu dengan adanya pendekatan proaktif terhadap pendeketan kepada nasabah.

\section{Penutup}

Hasil penelitian ini memberikan bukti empiris mengenai Pengaruh Program Layanan Jemput Maslahah terhadap Intensitas Penggunaan Tabungan Mudharabab: Studi pada PT.BJB Syariah di Kabupaten Bandung. Penelitian ini menggunakan sampel 125 responden, yang merupakan pedagang dipasar dan guru sekolah dimulai dari SD, SMP, SMA. Hasil dari penelitian menunjukan:

1. Program Layanan Jemput Maslahah mempengaruhi jumlah Tabungan Mudharabah secara positif dapat diterima.

2. Kepuasan dapat memediasi secara positif hubungan antara Layanan Jemput Maslahah dengan Tabungan Mudharabah dapat diterima. 
3. Kepercayaan dapat memediasi secara positif hubungan antara Layanan Jemput Maslahah dengan Tabungan Mudharabah dapat diterima.

Berdasarkan dari hasil analisis yang telah dipaparkan adapun beberapa saran sebagai berikut:

1. Diharapkan bagi peneliti yang akan datang dapat menambah responden yang memiliki cakupan wilayah yang sangat luas seperti provinsi Jawa Barat, karena penelitian ini belum tentu sesuai apabila diaplikasikan di wilayah Jawa Barat.

2. Diharapkan bagi peneliti yang akan datang dapat menambah variabel mediator seperti loyalitas, nisbah bagi hasil ataupun yang lainnya agar mendapatkan hasil yang lebih baik.

3. Diharapkan bagi peneliti yang akan datang metode sampling yang digunakan lebih ideal, seperti menggunakan sampling kuota.

\section{Daftar Pustaka}

Adewale, Adegbite Ganiu, Ademola Joshua Adeniran, Dan Solomon Ayodele Oluyinka. 2019. "The Effect Of Personal Selling And Marketing On Firm Sales The Effect Of Personal Selling And Marketing On Firm Sales Growth ( A Study Of Pz And Dangote Nigeria Plc )." Journal Of Business Management 5 (January).

Almana, La Ode, Sudarmanto, Dan Ismail Suardi Wekke. 2018. Tata Kelola Perguruan Tinggi Berbasis Akreditasi Penjamin Mutu Dan Pengelolaan Pengetahuan Di Pendidikan Tinggi. Edisi 1. Yogyakarta: Cv Budi Utama. Appasaheb, Yevale Naganth. 2018. Primary Teacher's Job Satisfaction. United States: Lulu Publications.

Damsar, Dan Indrayani. 2016. Pengantar Sosiologi Eknonomi. Cetakan Ke. Jakarta: Prenadamedia Group.

Erliana, Nelly. 2018. "Pengaruh Persepsi Layanan Jemput Zakat Terhadap Kepuasan Muzakki Di Lembaga Amil Zakat Yatim Mandiri Cabang Jombang." Ekonimi Islam 1 (2): 120-28.

Fitria, Novy. 2015. "Pengaruh Stres Kerja Dan Iklim Organisasi Terhadap Turnover Intention Dengan Kepuasan Kerja Sebagai Variabel Intervening Pada Perawat Rs. X Di Surabaya." Jurnal Ekonomi 11 (2): 256-72.

Fungáv, Zuzana, Iftekhar Hasan, Laurent Weill, Dan Oliver Wendell Holmes. 2017. "Trust In Banks." Journal Of Economic Behaviour \& Organization.

Honan, Cynthia A, Rhonda F Brown, Dan Jennifer Batchelor. 2015. "Perceived Cognitive Dif Fi Culties And Cognitive Test Performance As Predictors Of Employment Outcomes In People With Multiple Sclerosis." Journal Of The International Neuropsychological Society, 156-68.

Kemenag. 2016. “Kementerian Agama Dalam Angka Tahun 2016.” Kementrian Agama.

Kurniawan, Hironimus Hari. 2017. "Pengaruh Perceived Quality Terhadap Brand Loyalty Melalui Mediasi Brand Image Dan Brand Trust. (Studi Pada Brand Restoran Mcdonald's Di Kota Malang) Hironimus Hari Kurniawan.” Jurnal Bisnis Dan Manajemen 4 (2): 228-39.

Kwon, Jun-Gun, Dan Jun-Young Lee. 2015. “Are Adolescents With Internet Addiction Prone To Aggressive Behavior? The Mediating Effect Of Clinical Comorbidities On The Predictability Of Aggression." Journal Cybersychology, Behaviour And Social Networking 18 (5): 1-8.

Luk, Sherriff T.K., Ben S.C. Liu, Dan Esther L.Y. Li. 2018. "Effect Of Multilevel Trust On EffortIn-Use And Service Co-Design Behaviour." Journal Of Services Marketing 32 (4): 505-19.

Murithi, Murianki Morris. 2015. "Effects Of Personal Selling On Sales : A Case Of Women Groups In Imenti North District, Meru County , Kenya." International Journal Of Academic Research In Business And Social Sciences 5 (1): 38-52.

Mutaqqin, Galih Fajar, Dan Rita Dharmayanti. 2015. "Pengaruh Implementasi Total Quality 
Management Terhadap Kinerja Keuangan Dengan Kualitas Kinerja Sebagai Variabel Intervening." Jurnal Akuntansi Xix (01): 68-78.

Nuralam, Inggang Perwangsa. 2018. Manajemen Hubungan Pelanggan Perbankan Syaria Di Indonesia. Cetakan Pe. Yogyakarta: Cv Budi Utama.

Otoritas Jasa Keuangan, N.D. Roadmap Perbankan Syariah Indonesia 2015-2019.

Otoritas Jasa Keuangan. Snapshot Perbankan Syariah Indonesia 2019.

Panjaitan, Tika Hapsaroni. 2016. "Pengaruh Personal Selling Terhadap Keputusan Pembelian ( Studi Kasus Pt Millenium Pharmacon Internasional Tbk Cabang Bandung )." E-Proceeding Of Applied Science 2 (2): 448-57.

Rahmi, Yulia, Bambang Soedijono, Dan Hanif Al Fatta. 2017. "Analisis Penerapan Sistem Informasi Dosen Dan Karyawan ( Simdoskar ) Menggunakan Model Unified Theory Of Acceptance And Use Of Technology ( Utaut) Terhadap Perilaku Pengguna Teknik Pengambilan Sampel Menggunakan Sampel Acak Sederhana Atau Lebih Dikenal D” 2 (2): 109-17.

Rama, Ali. 2015. “Analisis Deskriptif Perkembangan Perbankan Syariah Di Asia Tenggara," The Journal Of Tauhidinomics, Vol 1 No 2: 105-28.

Risfandy, Tastafiyan, Putri Permatasari Husa, Dan Andi Asrihapsari. 2016. "Daya Saing Bank Syariah Di Sebuah Negara Religius: Temuan Empirik Dari Indonesia,” Jurnal Keuangan Dan Perbankan, 20 No 2 (Mei): 282-91.

Sahanggamu, Stefhanie, Lisbeth Mananeke, Dan Jantje Sepang. 2015. “Analisis Kualitas Layanan, Servicescape Dan Kepercayaan Terhadap Kepuasan Nasabah Pada Pt Bank Sinarmas Bitung." Emba 3 (1): 1084-95.

Sugiyono. 2018. Metode Penelitian Bisnis. Cetakan Ke. Bandung: Cv Alfabeta.

Suhartanto, D., Farhani, N. H., \& Muflih, M. (2018). Loyalty Intention towards Islamic Bank: The Role of Religiosity, Image, and Trust. International Journal of Economics \& Management, 12(1).

Suhartanto, D., Gan, C., Sarah, I. S., \& Setiawan, S. (2019). Loyalty towards Islamic banking: service quality, emotional or religious driven?. Journal of Islamic Marketing.

Usada, Untung, Luqman Hakim, Dan Anita T Kurniawati. 2016. "Analisis Pengaruh Kualitas Pelayanan Unusida Dengan Pendekatan Partial Least Square ( Pls )." Journal Of Research And Technology 2 (2).

Wardana, Fikri C. 2013. Creative Selling. Edisi 1. Jakarta: Pt Bhuana Ilmu Populer.

Wibisono, Dermawan. 2003. Riset Bisnis Panduan Bagi Praktisi Dan Akademisi. I. Jakarta: Pt Gramedia Pustaka Utama.

Wicaksonno, Driyanto Wahyu, Bagus Putu Yudha, Dan Hariadi Subagja. 2015. "Pengaruh Personal Selling,Kualitas Produk Terhadap Keputusan Pembelian Melalui Kepuasan Konsumen Di Toko Bagiak Pelangi Sari Banyuwangi.” Jurnal Ilmiah Inovasi 15 (3).

Yunis, Roni, Fauziatul Laila Ibsah, Dan Desi Arisandy. 2017. “Analisis Kesuksesan Penerapan Sistem Informasi Data Pokok Pendidikan (Dapodik) Pada Sd Kabupaten Batu Bara." Jurnal Sifo Mikroskil 18 (1): 71-82. Https://Doi.Org/14120100.

Zuliatin. 2016. "Pengaruh Personal Selling, Direct Selling Dan Hubungan Masyarakat Terhadap Kepuasan Nasabah Studi Kasus pada BMT UGT Sidogiri KCP Kanigoro Blitar" 3 NO 1 (Oktober): 93. 